\title{
Collapsin Response Mediator Protein 1, a Novel Marker Protein for Differentiated Odontoblasts
}

\author{
Toshihiro Miyazaki ${ }^{1}$, Tomomi T. Baba ${ }^{2}$, Masako Mori ${ }^{1}$ and Toshihisa Komori ${ }^{1}$ \\ ${ }^{1}$ Department of Cell Biology, Unit of Basic Medical Sciences, Nagasaki University Graduate School of Biomedical Sciences, \\ Nagasaki, Japan and ${ }^{2}$ Department of Oral Molecular Biology, Unit of Basic Medical Sciences, Nagasaki University Graduate \\ School of Biomedical Sciences, Nagasaki, Japan
}

Received August 30, 2018; accepted September 27, 2018; published online November 3, 2018

\begin{abstract}
We previously reported that the terminal differentiation of odontoblasts was inhibited in Runx2 transgenic $\{\mathrm{Tg}(\mathrm{Col} / \mathrm{a} 1-\mathrm{Run} \times 2)\}$ mice under the control of the 2.3-kb Col1a1 promoter. Odontoblasts in $T g($ Col1a1-Runx2) mice lose their characteristic long cellular processes, and show marked reductions in the protein levels of markers for odontoblasts, such as dentin sialophosphoprotein, nestin, and microtubule-associated protein tau (Mapt). We herein demonstrated that collapsin response mediator protein 1 (CRMP1), a neuronal phosphoprotein that participates in various aspects of neuronal development, was specifically expressed in the differentiated odontoblasts of wild-type, but not $T g(C o l 1 a 1-$ Runx2) tooth germs by comparing expression profiles in wild-type and $T g(C o l 1 a 1-R u n x 2)$ mouse molars using microarray and immunohistochemical analyses. CRMP1 expression was detected at a slightly later differentiation stage in odontoblasts than type 1 collagen, nestin, and Mapt expression, which was observed from the onset of dentinogenesis. Among these proteins, CRMP1 was the most specifically localized in odontoblasts in the tooth germ. In erupted molars, odontoblast-specific CRMP1 expression decreased with age. These results indicate that CRMP1 is a novel marker protein for differentiated odontoblasts in mouse tooth germs, and suggest that CRMP1 participates in the morphogenesis of functioning odontoblasts.
\end{abstract}

Key words: collapsin response mediator protein 1 (CRMP1), odontoblasts, Runx2

\section{Introduction}

Odontoblasts are specialized cells that are responsible for dentinogenesis, and differentiate from neural crestderived cells of dental papillae $[3,13]$. They are highly polarized cells that extend long processes into the dentinal tubules of dentine $[3,11,22]$, and share structural and gene expression similarities with neurons $[5,6,14]$. However, the mechanisms underlying the formation of their unique cell morphology remain unknown. Although BMP/TGF $\beta$ and Wnt10a signaling pathways have been implicated in

Correspondence to: Toshihisa Komori, MD., PhD., Department of Cell Biology, Unit of Basic Medical Sciences, Nagasaki University Graduate School of Biomedical Sciences, 1-7-1 Sakamoto, Nagasaki 852-8588, Japan. E-mail: komorit@nagasaki-u.ac.jp the terminal differentiation of odontoblasts from dental papilla cells [4], essential factors for the formation of odontoblastic processes have not yet been identified.

Runx 2 is an essential transcription factor not only for the osteoblast differentiation and terminal differentiation of chondrocytes [12, 19, 30], but also for odontoblast differentiation $[1,8]$. We previously analyzed Runx2 transgenic mice under the control of the $2.3-\mathrm{kb}$ Collal promoter $\{\operatorname{Tg}$ (Colla1-Runx2) mice $\}$ and demonstrated that Runx2 inhibited the terminal differentiation of odontoblasts [15]. In $T g$ (Colla1-Runx2) mouse molars, odontoblasts lost their polarity and long cellular processes, and the expression levels of odontoblast marker proteins, including dentin sialophosphoprotein and nestin, were markedly reduced. Furthermore, a comparison of the gene expression profiles of 
molars in wild-type and $\operatorname{Tg}($ Colla1-Runx2) mice revealed that microtubule-associated protein tau (Mapt), which is a neuronal phosphoprotein that plays important roles in neuronal biology as well as microtubule dynamics and assembly, was strongly and specifically expressed in the odontoblasts of wild-type mouse molars [16]. Since the expression of Mapt was markedly reduced in $\mathrm{Tg}$ (CollalRunx2) mouse molars, we suggested that Mapt participates in odontoblast morphogenesis, including the formation of cell processes, by regulating microtubule organization.

Collapsin response mediator protein 1 (CRMP1) is a member of the CRMP family, which is composed of five neuronal phosphoproteins (CRMP1-5) that are involved in neuronal development, maintenance, function, and disease $[17,21,29]$. In neuronal development, CRMP1 participates in neuronal cell migration, dendritic spine development, and synaptic plasticity $[7,25,27,28]$. We herein demonstrate that CRMP1, the expression of which was also markedly reduced in $\mathrm{Tg}$ (Colla1-Runx2) mouse molars, is a novel odontoblast-specific protein in mouse tooth germs.

\section{Materials and Methods}

\section{Animals}

Wild-type and $\operatorname{Tg}($ Colla1-Runx2) mice were maintained on a $\mathrm{B} 6 \mathrm{C} 3 \mathrm{H}$ F1 background. Prior to the present study, all experiments were reviewed and approved by the Animal Care and Use Committee of Nagasaki University Graduate School of Biomedical Sciences (No. 1403111129-20).

\section{Gene expression microarray and real-time RT-PCR}

Total RNA was extracted from the first and second molars of wild-type and $\operatorname{Tg}$ (Colla1-Runx2) mice at 14 days of age using the acid guanidine thiocyanate-phenolchloroform method according to the manufacturer's instructions (Isogen, Nippon Gene, Tokyo, Japan). In the microarray analysis, poly(A) mRNA was purified from total RNA using the Oligotex kit (Takara, Tokyo, Japan). cRNA was amplified, labeled, and hybridized to Agilent SurePrint G3 Mouse Gene Expression Microarray $8 \times 60 \mathrm{~K}$ (Agilent Technologies, Santa Clara, CA). Hybridized microarray slides were scanned using an Agilent scanner. Relative hybridization intensities and background hybridization values were calculated using Agilent Feature Extraction Software (ver. 9.5.1.1). A real-time RT-PCR analysis was performed using the following primers as previously described [16]: CRMP1, 5'-CCCTGGAGGAGGGAATAA GAAG-3' and 5'-AGGTGCCGTGGAGATGTGT-3'; $\beta$ actin, 5'-CCACCCGCGAGCACAGCTTC-3' and 5'-TTGT CGACGACCAGCGCAGC-3'. We normalized values to that of $\beta$-actin.

\section{Immunohistochemistry}

Immunohistochemical analyses were conducted using 3-, 7-, 14-, and 21-day-old, 6- and 10-week-old, and 6- month-old mice. After anesthetization by an intraperitoneal injection of sodium pentobarbital, mice were perfused with $4 \%$ paraformaldehyde in $0.05 \%$ cacodylate buffer ( $\mathrm{pH} 7.4$ ), and dissected molars were further immersed in the same fixative at $4^{\circ} \mathrm{C}$ for $24 \mathrm{hrs}$. Tissues were then decalcified in $5 \%$ EDTA (pH 7.4) at $4^{\circ} \mathrm{C}$ for 1 day to 4 weeks and embedded in paraffin. Sections (thickness of $4 \mu \mathrm{m}$ ) were immunostained as described below for the detection of CRMP1, nestin, pro-collagen type 1a1 (Col1a1), and Mapt. A polyclonal rabbit anti-CRMP antibody (1:500 dilution; Abcam, Cambridge, UK), monoclonal mouse anti-nestin antibody (1:500 dilution; Chemicon International Inc., CA, USA), polyclonal rabbit anti-Col1a1 antibody (1:250 dilution; EMD Millipore Corp., CA, USA), and polyclonal rabbit anti-Mapt antibody (1:400 dilution; Dako, Glostrup, Denmark) were used as primary antibodies. Normal rabbit IgG (Dako, Glostrup, Denmark) for CRMP1, Col1a1, and Mapt, and normal mouse $\mathrm{IgG}_{1}$ (Dako, Glostrup, Denmark) for nestin were used as negative controls instead of the primary antibodies. After blocking endogenous peroxidase activity with $0.3 \% \mathrm{H}_{2} \mathrm{O}_{2}$ in methanol, sections were processed with Histofine Simple Stain MAX-PO (R) (Nichirei) for CRMP1, Colla1, and Mapt antibodies, and the Histofine Mouse Stain Kit (Nichirei, Tokyo, Japan) for nestin. Antibody-binding sites were colored brown by an incubation with Histofine Simple Stain DAB solution (Nichirei). Sections were then counterstained with methyl green.

\section{Results and Discussion}

We previously investigated differentially expressed genes between $\mathrm{Tg}$ (Colla1-Runx2) and wild-type mouse molars by a microarray analysis, and the genes belonging to four Gene Ontology (GO) terms including the word "cytoskeleton" were significantly enriched, while 38 genes with these GO terms were down-regulated (Z-score $<-2.0$ and ratio $<0.66)$ in $\operatorname{Tg}($ Colla1-Runx2) mouse molars [16]. In the present study, we selected 8 out of the 38 genes, for which signal intensities were greater than 100 in wild-type molars and expression in $\mathrm{Tg}$ (Col1a1-Runx2) mouse molars was markedly reduced (Z-score $<-3.0$ and ratio $<0.2$-fold) (Table 1). Since odontoblasts share similar structures and gene expression patterns with neurons $[5,6,14]$, we focused on genes that are predominantly expressed in the nervous system. CRMP1 (signal intensity in wild-type = 464.53, Z-score $=-3.72$, ratio $=0.18$ ) as well as Mapt and Nestin, which were previously reported $[15,16]$, matched our focus. The validity of microarray data for CRMP1 expression was confirmed by real-time RT-PCR (Fig. 1). The expression level of CRMP1 in $T g$ (Colla1-Runx2) molars was 0.05 -fold that in wild-type molars, which consistent with and confirmed the accuracy of data obtained in the microarray analysis.

We examined the localization of CRMP1 in mouse molars by immunohistochemistry, and found that CRMP1 
Table 1. List of down-regulated genes in Tg(Collal-Runx2) molars, which were included in significant Gene Ontology terms with the word "cytoskeleton" and showing signal intensity over 100 in wild-type molars and markedly reduced fold changes (Z-score $<-3.0$ and ratio $<0.2$-fold) in $\mathrm{Tg}$ (Colla1-Runx2) molars

\begin{tabular}{|c|c|c|c|c|}
\hline Accessions & Genes & Signal intensity of wild-type & Z-score & ratio \\
\hline NM_011474 & small proline-rich protein $2 \mathrm{H}$ (Sprr2h) & 397.08 & -4.90 & 0.10 \\
\hline NM_001136058 & collapsin response mediator protein $1(\mathrm{Crmp} 1)$ & 464.52 & -3.72 & 0.18 \\
\hline NM_182992 & myopalladin (Mypn) & 575.88 & -4.50 & 0.12 \\
\hline NM_198649 & actin binding LIM protein family, member 3 (Ablim3) & 6754.71 & -4.95 & 0.16 \\
\hline NM 009922 & calponin $1(\mathrm{Cnn} 1)$ & 8243.43 & -5.96 & 0.11 \\
\hline NM 009132 & scinderin (Scin) & 8560.91 & -4.95 & 0.16 \\
\hline NM_001038609 & microtubule-associated protein tau (Mapt) & 16443.69 & -5.35 & 0.14 \\
\hline NM_016701 & nestin (Nes) & 20693.09 & -6.37 & 0.14 \\
\hline
\end{tabular}

* Z-scores and ratios (non-log-scaled fold change) were calculated from the normalized signal intensities of each probe for comparison between wild-type and $\mathrm{Tg}$ (Colla1-Runx2) molars.

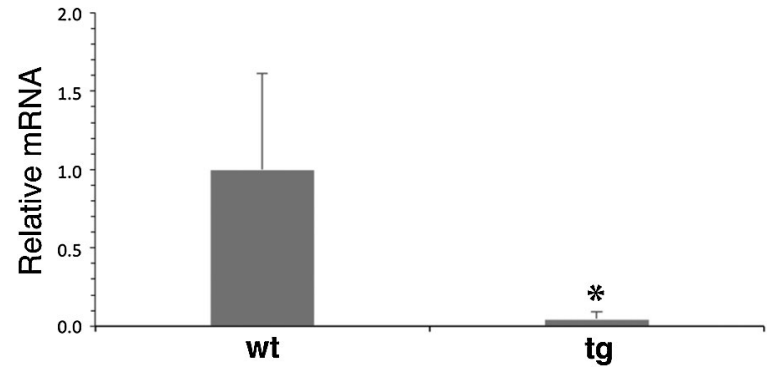

Fig. 1. Real-time RT-PCR analysis of CRMPI in tooth germs of 2-weekold mice. The value in wild-type (wt) mice was set as one and the relative level of $\operatorname{Tg}$ (Colal-Runx2) (tg) mice is shown. Data are the mean \pm $\mathrm{SD}$ of seven wild-type and six tg mice. $* \mathrm{P}<0.01$.
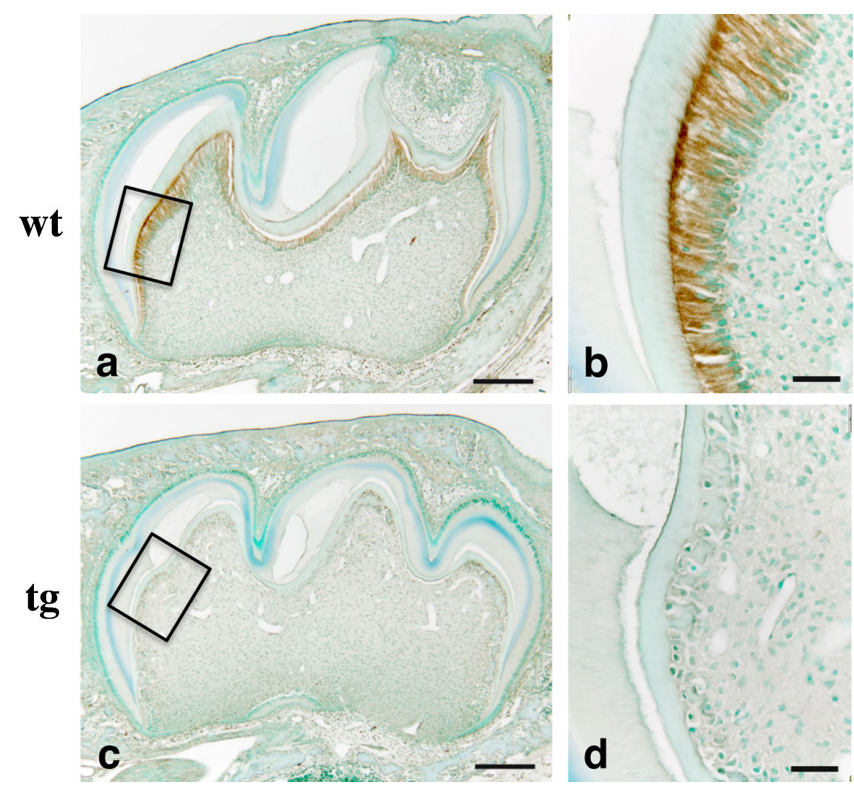

Fig. 2. Expression of the CRMP1 protein in tooth germs of first molars in wild-type (wt) (a, b) and $\operatorname{Tg}($ Collal-Runx2) (tg) (c, d) mice at 7 days of age. Boxed regions in $\mathbf{a}$ and $\mathbf{c}$ are magnified in $\mathbf{b}$ and $\mathbf{d}$, respectively. CRMP1 expression was exclusively detected in differentiated odontoblasts in wild-type mice, whereas it was negligibly expressed in the odontoblasts of $\operatorname{Tg}$ (Colla1-Runx2) mice. Bars $=200 \mu \mathrm{m}$ (a and c), $40 \mu \mathrm{m}$ (b and d).
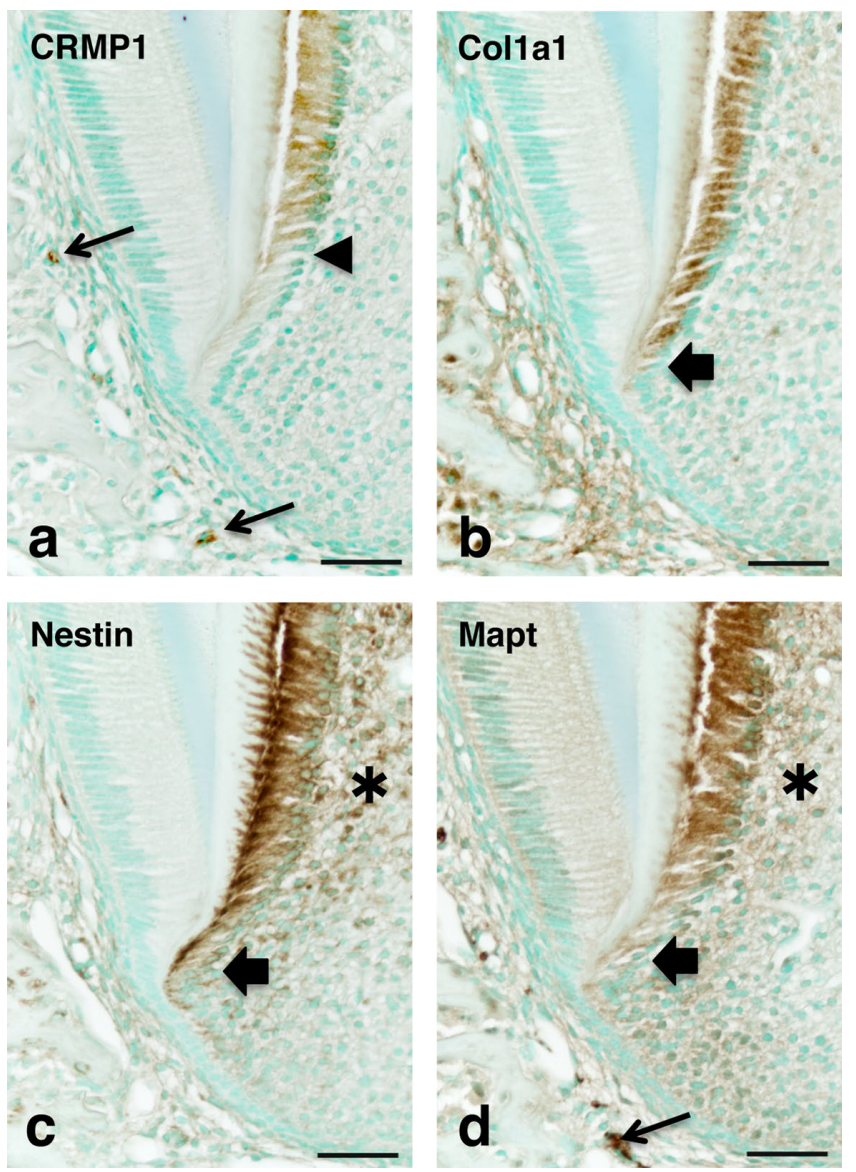

Fig. 3. Comparison of the expression of CRMP1 (a), Colla1 (b), nestin (c), and Mapt (d) in tooth germs of first molars in 7-day-old wild-type mice. The expression of Col1a1, nestin, and Mapt in odontoblasts appeared with the onset of dentinogenesis (thick arrows), while CRMP1 expression in odontoblasts appeared after the onset of dentinogenesis (arrow head). Nerve fibers were also positive for CRMP1 and Mapt (thin arrows). The expression of Colla1 was also observed in osteoblasts and collagen fibers, while that of nestin and Mapt was detected in dental pulp cells under the odontoblast layer (asterisks). Bars $=40 \mu \mathrm{m}$. 

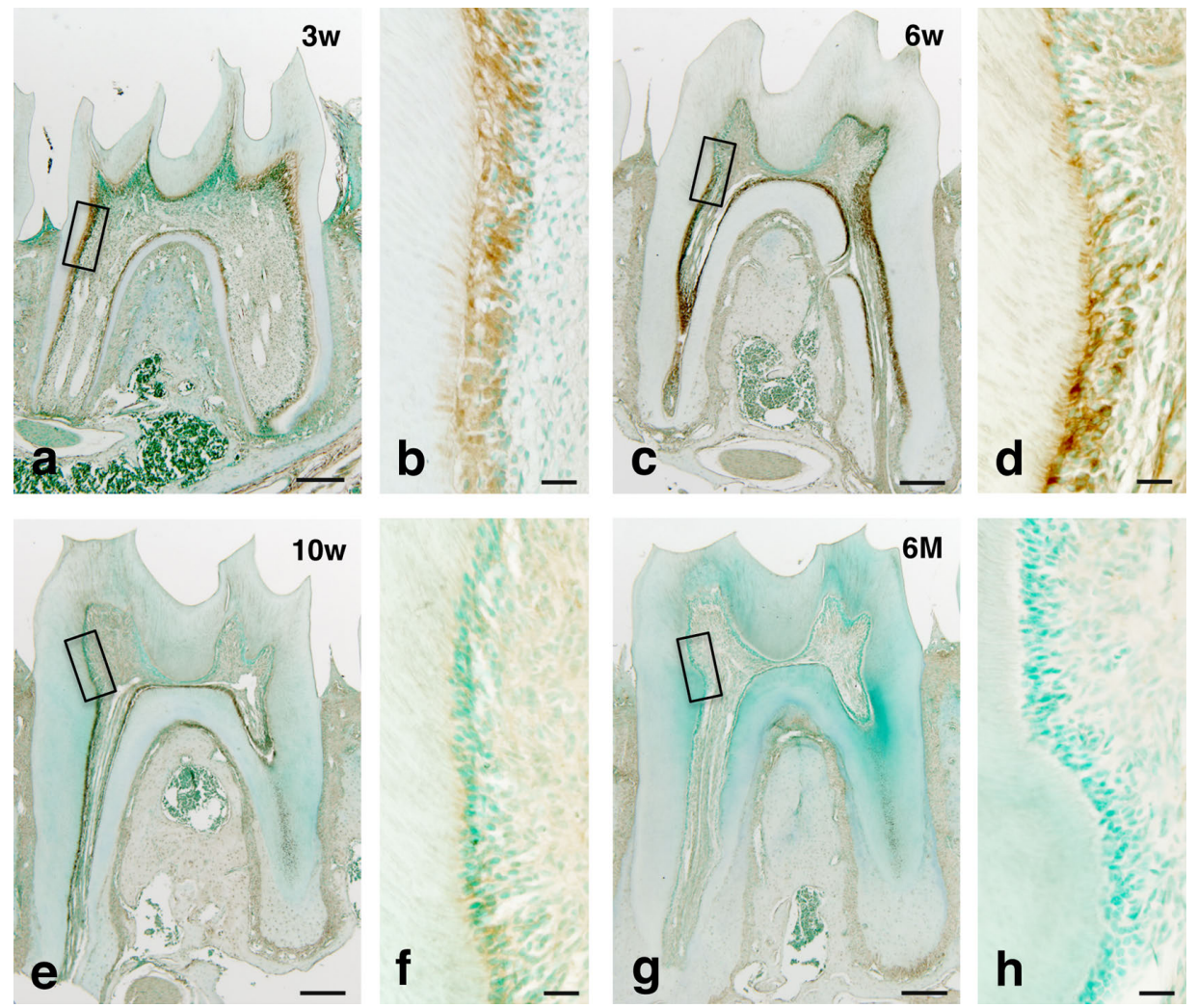

Fig. 4. Expression of the CRMP1 protein in erupted first molars in wild-type mice at 3 (a), 6 (c), and 10 weeks (e) and 6 months (g) of age. Cervical regions indicated by boxes in $\mathbf{a}, \mathbf{c}, \mathbf{e}$ and $\mathbf{g}$ are magnified in $\mathbf{b}, \mathbf{d}, \mathbf{f}$ and $\mathbf{h}$, respectively. CRMP1 expression was down-regulated with age, starting from the coronal region, and was not detected in the whole region at 6 months of age. Bars $=200 \mu \mathrm{m}(\mathbf{a}, \mathbf{c}, \mathbf{e}$ and $\mathbf{g}), 20 \mu \mathrm{m}(\mathbf{b}, \mathbf{d}, \mathbf{f}$ and $\mathbf{h})$.

was exclusively localized in the cytoplasm of differentiated odontoblasts and their processes in the tooth germs (Fig. 2a, b). CRMP1 expression was also detected in nerve fibers (Fig. 3a). In $\operatorname{Tg}$ (Colla1-Runx2) mouse molars, in which odontoblasts lost their characteristic polarized morphology, CRMP1 expression in odontoblasts was not detectable (Fig. $2 \mathrm{c}, \mathrm{d})$. The expression of the odontoblast marker proteins, type 1 collagen (Colla1), nestin, and Mapt was detected in differentiated odontoblasts with the onset of dentinogenesis in wild-type tooth germs, while CRMP1 expression was detected in odontoblasts at a slightly later differentiation stage than those for Colla1, nestin, and Mapt (Fig. 3). In addition to odontoblasts, Colla1 expression was detected in osteoblasts, fibroblasts, and collagen fibers, while nestin and Mapt expression was detected in dental pulp cells under the odontoblast layer (Fig. 3b-d). Therefore, among these proteins, CRMP1 was the most specifically localized in odontoblasts in the tooth germ (Fig. 3). These results support the applicability of CRMP1 as a useful marker protein for evaluating differentiated odontoblasts in mouse tooth germs even though its expression level was likely to be markedly lower than the other odontoblast marker proteins based on the signal intensities of microarray data (Table 1).

Microtubules are essential neuronal morphogenesis regulators, and CRMPs as well as MAPs are microtubule- regulating proteins. MAPs and CRMPs are categorized as microtubule-stabilizing proteins and microtubulepolymerizing proteins, respectively [20]. Previous studies reported that MAP2 and Mapt stabilized microtubules by binding along protofilaments [2], and CRMP2 bound to tubulin heterodimers to promote microtubule polymerization [9]. Since microtubules are essential constituents of odontoblast processes in addition to neurites $[10,18,23$, 24], CRMP1 may also be involved in odontoblast morphogenesis by regulating microtubule organization in cooperation with Mapt.

In erupted molars, the odontoblast-specific expression of CRMP1 was observed in most odontoblast layers at 3 weeks of age, decreased in coronal regions at 6 and 10 weeks of ages, and was not detectable in the whole region at 6 months of age (Fig. 4). The elongated odontoblasts at 3 weeks of age were taller than those at 6 months of age (Fig. 4), suggesting an association of CRMP1 expression and the morphology and function of odontoblasts. CRMP1 is strongly expressed in neurons after migration during brain development, but is down-regulated in the adult nervous system, except in the areas associated with brain plasticity or neurogenesis, such as the olfactory bulbs, hippocampus, and cerebellum [7, 26]. Since CRMP1 expression in odontoblasts also decreased with age, it may play an essential role in the morphogenesis of functioning 
odontoblasts during dentinogenesis.

In conclusion, CRMP1 is considered to be a novel marker protein for differentiated odontoblasts in mouse tooth germs, and may be an important microtubuleregulating protein for odontoblast morphogenesis in mice. Detailed studies on CRMP1 functions in dentinogenesis will be necessary in the future.

\section{Conflicts of Interest}

The authors declare that there are no conflicts of interest associated with this manuscript.

\section{Acknowledgments}

This work was supported by a Grant-in-Aid for Scientific Research from the Japan Society for the Promotion of Science (\#15K11015).

\section{References}

1. Aberg, T., Wang, X. P., Kim, J. H., Yamashiro, T., Bei, M., Rice, R., Ryoo, H. M. and Thesleff, I. (2004) Runx2 mediates FGF signaling from epithelium to mesenchyme during tooth morphogenesis. Dev. Biol. 270; 76-93.

2. Al-Bassam, J., Ozer, R. S., Safer, D., Halpain, S. and Milligan, R. A. (2002) MAP2 and tau bind longitudinally along the outer ridges of microtubule protofilaments. J. Cell Biol. 157; 11871196.

3. Arana-Chavez, V. E. and Massa, L. F. (2004) Odontoblasts: the cells forming and maintaining dentine. Int. J. Biochem. Cell Biol. 36 ; $1367-1373$.

4. Balic, A. and Thesleff, I. (2015) Tissue interactions regulating tooth development and renewal. Curr. Top. Dev. Biol. 115; $157-$ 186.

5. Bleicher, F., Couble, M. L., Buchaille, R., Farges, J. C. and Magloire, H. (2001) New genes involved in odontoblast differentiation. Adv. Dent. Res. 15; 30-33.

6. Buchaille, R., Couble, M. L., Magloire, H. and Bleicher, F. (2000) A substractive PCR-based cDNA library from human odontoblast cells: identification of novel genes expressed in tooth forming cells. Matrix Biol. 19; 421-430.

7. Charrier, E., Mosinger, B., Meissirel, C., Aguera, M., Rogemond, V., Reibel, S., Salin, P., Chounlamountri, N., Perrot, V., Belin, M. F., Goshima, Y., Honnorat, J., Thomasset, N. and Kolattukudy, P. (2006) Transient alterations in granule cell proliferation, apoptosis and migration in postnatal developing cerebellum of CRMP1-/- mice. Genes Cells 11; 1337-1352.

8. D’Souza, R. N., Aberg, T., Gaikwad, J., Cavender, A., Owen, M., Karsenty, G. and Thesleff, I. (1999) Cbfa1 is required for epithelial-mesenchymal interactions regulating tooth development in mice. Development 126; 2911-2920.

9. Fukata, Y., Itoh, T. J., Kimura, T., Menager, C., Nishimura, T., Shiromizu, T., Watanabe, H., Inagaki, N., Iwamatsu, A., Hotani, H. and Kaibuchi, K. (2002) CRMP-2 binds to tubulin heterodimers to promote microtubule assembly. Nat. Cell Biol. 4; 583-591.

10. Garant, P. R. (1972) The organization of microtubules within rat odontoblast processes revealed by perfusion fixation with glutaraldehyde. Arch. Oral Biol. 17; 1047-1058.

11. Goldberg, M. and Smith, A. J. (2004) Cells and extracellular matrices of dentin and pulp: a biological basis for repair and tissue engineering. Crit. Rev. Oral Biol. Med. 15; 13-27.

12. Komori, T., Yagi, H., Nomura, S., Yamaguchi, A., Sasaki, K., Deguchi, K., Shimizu, Y., Bronson, R. T., Gao, Y. H., Inada, M., Sato, M., Okamoto, R., Kitamura, Y., Yoshiki, S. and Kishimoto, T. (1997) Targeted disruption of Cbfa1 results in a complete lack of bone formation owing to maturational arrest of osteoblasts. Cell 89; 755-764.

13. Linde, A. and Goldberg, M. (1993) Dentinogenesis. Crit. Rev. Oral Biol. Med. 4; 679-728.

14. Maurin, J. C., Couble, M. L., Staquet, M. J., Carrouel, F., About, I., Avila, J., Magloire, H. and Bleicher, F. (2009) Microtubuleassociated protein $1 \mathrm{~b}$, a neuronal marker involved in odontoblast differentiation. J. Endod. 35; 992-996.

15. Miyazaki, T., Kanatani, N., Rokutanda, S., Yoshida, C., Toyosawa, S., Nakamura, R., Takada, S. and Komori, T. (2008) Inhibition of the terminal differentiation of odontoblasts and their transdifferentiation into osteoblasts in Runx2 transgenic mice. Arch. Histol. Cytol. 71; 131-146.

16. Miyazaki, T., Baba, T. T., Mori, M., Moriishi, T. and Komori, T. (2015) Microtubule-associated protein tau (Mapt) is expressed in terminally differentiated odontoblasts and severely downregulated in morphologically disturbed odontoblasts of Runx2 transgenic mice. Cell Tissue Res. 361; 457-466.

17. Nagai, J., Baba, R. and Ohshima, T. (2017) CRMPs function in neurons and glial cells: potential therapeutic targets for neurodegenerative diseases and CNS injury. Mol. Neurobiol. 54; 4243-4256.

18. Nishikawa, S. and Kitamura, H. (1987) Microtubules, intermediate filaments, and actin filaments in the odontoblast of rat incisor. Anat. Rec. 219; 144-151.

19. Otto, F., Thornell, A. P., Crompton, T., Denzel, A., Gilmour, K. C., Rosewell, I. R., Stamp, G. W., Beddington, R. S., Mundlos, S., Olsen, B. R., Selby, P. B. and Owen, M. J. (1997) Cbfa1, a candidate gene for cleidocranial dysplasia syndrome, is essential for osteoblast differentiation and bone development. Cell 89; 765-771.

20. Poulain, F. E. and Sobel, A. (2010) The microtubule network and neuronal morphogenesis: Dynamic and coordinated orchestration through multiple players. Mol. Cell. Neurosci. 43; 15-32.

21. Quach, T. T., Honnorat, J., Kolattukudy, P. E., Khanna, R. and Duchemin, A. M. (2015) CRMPs: critical molecules for neurite morphogenesis and neuropsychiatric diseases. Mol. Psychiatry $20 ; 1037-1045$.

22. Ruch, J. V., Lesot, H. and Begue-Kirn, C. (1995) Odontoblast differentiation. Int. J. Dev. Biol. 39; 51-68.

23. Sasaki, T. and Garant, P. R. (1996) Structure and organization of odontoblasts. Anat. Rec. 245; 235-249.

24. Sigal, M. J., Aubin, J. E. and Ten Cate, A. R. (1985) An immunocytochemical study of the human odontoblast process using antibodies against tubulin, actin, and vimentin. J. Dent. Res. 64; 1348-1355.

25. Su, K. Y., Chien, W. L., Fu, W. M., Yu, I. S., Huang, H. P., Huang, P. H., Lin, S. R., Shih, J. Y., Lin, Y. L., Hsueh, Y. P., Yang, P. C. and Lin, S. W. (2007) Mice deficient in collapsin response mediator protein-1 exhibit impaired long-term potentiation and impaired spatial learning and memory. $J$. Neurosci. 27; 2513-2524.

26. Wang, L. H. and Strittmatter, S. M. (1996) A family of rat CRMP genes is differentially expressed in the nervous system. J. Neurosci. 16; 6197-6207.

27. Yamashita, N., Uchida, Y., Ohshima, T., Hirai, S., Nakamura, F., Taniguchi, M., Mikoshiba, K., Honnorat, J., Kolattukudy, P., Thomasset, N., Takei, K., Takahashi, T. and Goshima, Y. (2006) Collapsin response mediator protein 1 mediates reelin signaling in cortical neuronal migration. J. Neurosci. 26; 13357-13362. 
28. Yamashita, N., Morita, A., Uchida, Y., Nakamura, F., Usui, H., Ohshima, T., Taniguchi, M., Honnorat, J., Thomasset, N., Takei, K., Takahashi, T., Kolattukudy, P. and Goshima, Y. (2007) Regulation of spine development by semaphorin3A through cyclin-dependent kinase 5 phosphorylation of collapsin response mediator protein 1. J. Neurosci. 27; 12546-12554.

29. Yamashita, N. and Goshima, Y. (2012) Collapsin response mediator proteins regulate neuronal development and plasticity by switching their phosphorylation status. Mol. Neurobiol. 45;
234-246.

30. Yoshida, C. A., Yamamoto, H., Fujita, T., Furuichi, T., Ito, K., Inoue, K., Yamana, K., Zanma, A., Takada, K., Ito, Y. and Komori, T. (2004) Runx2 and Runx3 are essential for chondrocyte maturation, and Runx2 regulates limb growth through induction of Indian hedgehog. Genes Dev. 18; 952-963.

This is an open access article distributed under the Creative Commons Attribution License, which permits unrestricted use, distribution, and reproduction in any medium, provided the original work is properly cited. 